\title{
Greg: Response to Lauren
}

Without reading each other's editorial pieces and restraining from conversing about them, both editorials' essences coincide closely. Both discuss our roles within CIE but differ in contexts - mine begins with my initial teaching in courses, arguing that understanding education, or anything, is inherently done through comparisons. Lauren richly describes her work within diverse communities (e.g., academic societies, publication teams) to better understand CIE dialectically within and between her geographic and metaphoric "homes". In all our work, we describe our own positionalities, as it is essential for any research because all research is subjective and political (Harding, 1991) - an argument that we both develop in our editorials. We both highlight the politics and subjectivity of CIE and its nearly endless possibilities, or, as might be worded using Freire's terminology in the first chapter of Pedagogy of the Oppressed (2000), as "unfinishedness" of CIE. Aligned with Freirean "reinvention," we both condemn education leading to instilling fatalism within students, CIE work that sustains fatalistic education systems, and CIE the does not reinvent itself but rather instills ideologies of finishness in the field. I read Lauren's use of the playful term "epistemological nimbleness" in her title as the need for reinvention. As Freireans, we understand reinvention as not blindly eliminating or delegitimizing CIE cannons but rather utopian acts of "announcing and denouncing," as Freire described below, for contextual transformation towards ending oppressions and planetary unsustainability.

Denouncing and announcing, when part of the process of critically reading the world, give birth to the dream for which one fights. This dream or vision, whose profile becomes clear in the process of critically analyzing the reality one denounces, is a practice that transforms society, just as the drawings of a unit a factory worker is to build, which he or she has in his or her head before making it, makes possible the actual manufacturing of the unit. (p. 18) (Freire, 2004, p. 18)

For example, how can we transform CIE contextually within our changing world to denounce reproduction of oppressions from education to announce beneficial lending and borrowing? Many CIE scholars have disputed against some of the arguments that we give, such as post-foundationalism (in Lauren's editorial) and countering epistemologies of the North, seeing it as blindly 
denouncing all traditional cannons. The phrase of "throwing the baby out with the bath water" comes to mind. However, what we argue is for critically reading and re-reading the needs of reinventing traditional cannons, possibilities for newly established methodologies, and recognizing the need for CIE work grounded in epistemologies of the South and legitimizing CIE work from the Global South.

\section{References}

Freire, P. (2000). Pedagogy of the oppressed. New York, NY: Continuum.

Freire, P. (2004). Pedagogy of indignation. Boulder, CO: Paradigm Publishers.

Harding, S. G. (1991). Whose science? Whose knowledge?: Thinking from women's lives. Ithaca: Cornell University Press. 